\title{
The Caucasus as an Eternal Frontier
}

\author{
Anna Romanova, Mikhail Topchiev, Baeva Liudmila \\ Humanitarian institute, Astrakhan State University, 20a Tatishchev str., 414056 Astrakhan, Russian Federation \\ aromanova_mail@mail.ru,dc_mail@bk.ru,baevaludmila@mail.ru
}

\begin{abstract}
Based on the example of the analysis of social and cultural processes the article shows epistemic opportunities of the frontier theory proposed by F.J. Turner and received further development in foreign and Russian researches. The authors of the article assess current state of the frontier theory and compare different versions of the frontier typology. A special attention is paid to a new typology earlier proposed by O.S. Yakushenkova, S.N. Yakushenkov and A.P. Romanova. This typology - early frontier, frontier, postfrontier and refrontier - was applied to the analysis of the Caucasian frontier change dynamics. The study resulted in revelation of new methodological opportunities of this typology allowing to analyze frontier not as complete historical phenomenon but as ongoing, dynamically changing social and cultural process. It makes possible to understand better the character of modern conflicts and confrontations of the main Caucasian frontier actors and to predict further development of intercultural communications in this region. This typology can be also applied to study other regions.

Index Terms - frontier, typology, refrontier, cultural communications, the Caucasus
\end{abstract}

\section{Introduction}

Since 1893, when the frontier theory was formulated by F.J. Turner on the American history materials and continued by many American researchers (R.A. Billington, R.W. Etulain, F. Paxson and others), it received development worldwide. It started to be applied for other territories, e.g. for India (R. B. Pemberton, G. Th. Bayfield, S. Cotton, S.S. Jeyaseela), Canada (E. Furniss ), Afganistan (V. Schofield) Australia (E. Furniss), Africa (O.M. Esaulova), Russia (M. Khodarkovsky, Joseph L.Weiczynski., Denis D.P.Show). Firstly these were the Siberian historians who studied the frontier in Russia (A.D. Ageev, D.Ya. Rezun, N.Yu.Zamyatina). Later on the frontier methodology was applied for the Far East (T.V.Vorobiyova, N.N.Prikhodko), Central Asia (V.A. Moiseev). There were some attempts to apply the theory for the Russian central territory (D.S.Zhukov, V.V.Kanishchev). Lately researchers have started to be interested in the Southern Russia - the territories of the Southern Federal District and the North Caucasian Federal District (Thomas M. Barrett, E.A. Sheudzhen, S.M. Markedonov, S.N.Yakushenkov, A.P.Romanova). An imprecise definition of frontier given by Turner himself as well as interesting results of the frontier methodology application for a number of territories led to the increase of the frontier theory epistemic role. While spreading the frontier idea got a new understanding and development. Frontier ceased to be mainly understood as a frontier territory between wildness and civilization. It also began to be considered as a territory between "ours and stranger" (S.N.Yakushenkov, O.S.Yakushenkova), as a break of two civilizations (A.D. Ageev), as a contact, dialogue zone of various cultures' meetings (A.S. Khromykh, I.Ya. Levyash) and so on. New versions of the frontier typology appeared. The main research topic of the article is modern cultural processes taking place in the North Caucasus. The main task for the authors is to mark out basic features of the Caucasian frontier, to examine its evolution and current state of communication processes on basis of the analysis of the existing frontier typology as well as the one earlier proposed by us.

\section{The Research Methodology}

In this case the main research methodology is the frontier approach itself to cultural and political processes taking place in the Caucasus. The frontier theory is ceasing to be just an instrument for historical research applied for processes having happened far back in the past. Its application for analysis of modern processes taking place on the historic frontier territories makes it possible for us to speak of frontier as an ongoing and modifying process. Frontier's heterotypic character allows us to apply synchronous and diachronous research methods at the same time and the deconstruction method allows to depart from a traditional linear approach to the frontier analysis. Frontiers' diversity, complexity of their typology and structuring require application of the comparative approach primarily in the sphere of cultural historical processes.

\section{Theoretical Basics of the Frontier Study: Current State}

Despite the fact that Turner gave an imprecise definition for a frontier one can reveal a whole set of frontier features while analyzing his work, e.g. border location of a populated territory; confrontation of wildness and civilization; resistance to authorities, freedom, democracy; liberalism; multiethnical and multiconfessional environment, religious freedom; individualism, negation of old customs, a new field of opportunities, etc. They are indicated by Turner in his texts [1] but are not systematized. However these features were supplemented and comprehended by his interpreters (A. G. Bogue, R. Hofstadter, R. Jensen) and followers (V. Prescott, G. D.Triggs, R.W. Etulain). Among the Russian researches in the area of the frontier theory and its criteria classifications the papers of I.Yu. Basalaeva [2] are the most informative. Due to the marking out of the criteria basic set one can single out several lines in the frontier study; these are geographical, civilizational, alternative ones. In the frontier study a particular place is taken by its typologization. Some typologization procedures were carried out by Turner himself. However R.A. Billington paid the greatest attention to this issue. His typology 
(more than 20 frontier types) was based on geographical and historical principles. The types or forms of frontier proposed by him (trapper, mining, trade ones...etc.) have a pronounced economic character. [3] In the Russian science there were also a number of attempts to structure and classify frontier processes. Three frontier structural elements - external, internal elements and intracivilizational one which characterizes a new form of relations between old residents and settlers - are marked out. [4] M.V. Shilovsky characterizes them as frontier types, A.S. Khromykh - as stages of the same frontier [5] and A.I. Shirokov stepping aside from a pure historical interpretation of frontier considers frontier as a wave process and admits the application of this methodology to the processes of Siberia settlement in the 20th century. [6] A new frontier typology was proposed by the Russian researcher O.S.Yakushenkova. Her typologization was based not just on a classical linear civilizational approach but on character of communication processes taking place on the frontier territories. Basing on the American material research she marks out three different types of frontier: early frontier, frontier and postfrontier; each of them is characterized by its own type of cultural dialogue. [6] This typology is well used for the one-direction linear American frontier. However within the study on processes taking place in the Southern Russia one can speak of a slightly different frontier model and, consequently, of its different typology. It will also differ even in different regions of the Southern Russia such as the Lower Volga and the North Caucasus. For the Caucasian frontier this typology was supplemented by S.N. Yakushenkov and A.P. Romanova with one more stage and, to some extent, a frontier type called "refrontier" [6]. Refrontier as a special type of communication relations on the frontier was marked out due to the researches of frontier processes in the Caucasus which have reversible character there. Refrontier is characterized by the destruction of communications having formed during the frontier and postfrontier stages, by confrontation of frontier zone actors as well as by different scenarios of its further development. To some extent re-frontier is an active modern frontier process.

\section{Specific Character and Typology of the Caucasian Frontier}

Still there is no answer to the question whether it is possible to consider the Caucasus as a frontier territory. Some researchers such as E.A. Sheudzhen [9] confidently negate this idea primarily basing on the fact that the main frontier feature is a contact of wildness and civilization and, to his point of view, at the time the Caucasus was an independent civilization. The author thinks that the search for the Caucasian frontier is not a methodological issue but a political action. However a number of researchers rather confidently refer the North Caucasus to the frontier zone (Thomas M. Barrett, S.M. Markedonov). For example, Barrett as a historian can use this approach to examine the Caucasian wars period not just in the context of war action conduct and fortification building but as a frontier taking into account communication peculiarities of such territories. But even he considers the Caucasian frontier as a historical fact. [10] To our point of view the Caucasus is not only the territory of a historical frontier but it currently preserves this state.

Although one must take into account the fact that the concept "Caucasian frontier" used by us in the article is quite relative because in fact this is a certain unity in the multiplicity of different frontier scenarios - the Chechen frontier, the Dagestanian frontier, etc. - which are conditional to regional, ethnic and natural peculiarities. However due to the territorial localization they have common development stages, frontier types of communication relations, specific character of processes' progressing.

A differential characteristic of the Caucasian frontier is that in contrast to the major part of the frontier territories the Caucasian frontier has got not just one but two active borders within its main stage: these are borders with Russia and with the Muslim East (Sublime Porte and Iran). This territory received cultural influence from two sides. From the Russian side these were such tendencies as Russification, economic and trade exchange, institutionalization of social political life of the Caucasian peoples. Influenced by the Ottomans the semi-Christian and semi-Pagan population of the Caucasus was converted to the Islam of the Sufism branch having given an ideological basis for the confrontational period (Mouridism) during the active frontier stage. However, the economic influence of the southern borders was also noted (e.g., the Persian rice and millet, the Ottoman grapes, etc.). In this article we will confine ourselves just with the analysis of the Russian and Caucasian side of the frontier.

A great part of the frontier features given by Turner are typical for this territory not only for the period of the Caucasian wars of the 18th-19th centuries but for the future periods as well. This territory was always border located and at the same time it was the territory of cultural dialogue occasionally passing into the stage of confrontation. Caucasian peoples, the Chechens in particular, have always been lovers of liberty, they have stood against governmentalization and institutionalization. That was a heterotopic territory where laws were reoriented, brigandage was almost a legitimized form of economic activity, brigands were considered heroes, many people were transiting from one side of the frontier to the other, religious and ethnic pluralism took place etc.

Using the typology of frontier given above (early frontier - frontier - postfrontier - refrontier) let us study the dynamics of its development in the Caucasus. First, one can clearly distinguish the stage of early frontier (16-17th cc), from the time the first fortified town was built on the river Terek by the cossacks or brigands [11] according to one version, by Ivan the Terrible in 1563 [12] as another version suggests, in the mouth of the river Sunzha in 1567 [10] as a third theory asserts. Heterotopic character of the territory has influenced its mythological understanding and multipolar nature of scientific guesses. In the fortresses, which were at all the times constructed and ruined and moved about, the Grebentsky 
cossacks, though few in number, had "close relations with the hill-folk" [12], thus promoting trade and favorable communication. Negligibly few narrative sources remained from that stage of early frontier.

Frontier stage is in the chronological aspect the period of the Caucasian war (18-19th cc). Its chronology is also varying in different narrative sources and historical papers. At this stage the cultural dialogue takes a form of confrontation, aggravated by active military actions from the part of Russia. The Caucasian peoples are divided into peaceful and nonpeaceful ones, though this division is quite conventional. The both parties perform bloody military activity and keep the count, like it used to be in American history when Indians counted scalps of the enemies, with the cut ears or heads, and that practice was common on the both sides of the frontier. [13] At this stage the institution of capture is functioning actively as well as the practice of amanats - hostages, that produce the respective types of frontier man. This context comprises all the classical characteristics of a frontier. Independent Caucasian mythology is being formed. Russian soldiers and officers campaigning in the Caucasus were particular freedom lovers, uninhibited, smart in comparison with the militants in the hinterland. Russian officers who fought in the Caucasus were called Caucasians. [14] This stage was characterized not only by transition from one side of the frontier to the other one, but also by religious exchange - the Caucasians were Christianizes, the Kazaks were converted into Islam. [15]

The third stage or type of the frontier - postfrontier - is the period of confrontation cease, frontier becoming a history of the region, reappraisal of values, formation of a certain new synthetic communicative culture. In the Caucasus there was no postfrontier stage in the traditional American understanding. For a deep hidden perception of "Russian occupation" was preserved even in the Soviet period. [15] Another sign of the long-drawn stage of the frontier is deportation of a number of Caucasian peoples by Stalin, inhabiting of the left houses by non-Caucasian ethnic groups, formation of certain reservation colonies for Caucasian ethnic groups in the regions of their exile. Their returning home was hard and painful. Since the late 1950s, in the period of Khruschev and Brezhnev governing, it looked as if a postfrontier culture started to form. Russification processes developed, the Russian language became an obligatory language of communication. Overall compulsory atheism and Marxism form a common ideological medium. Some representatives of the Caucasian elite are mythologized. The Caucasian region gets substantial economic backup. A system of communication restraining regulators is established. But the frontier situation was not reviewed internally. Perhaps that was impossible due to the historical and cultural nature of the region and because of the fact the history of the Caucasus was not considered an example of a frontier history. And the Chechnya wars and the present situation in Dagestan prove that fact.

At present a number of the Caucasian regions are at the refrontier stage. Actually this is the reversion to confrontational relations, replacement of dominant actors, reconsideration of historical process and creation of new mythology. The most expository example is the Chechen refrontier, as the confrontation resulted new wars here, with a new system of capture, freedom bordering with lawlessness, deserting to the enemy's forces, the Chechens being on the both sides of the frontier, unjustified savagery. At this stage despite the Russian army outnumbering and its formal victory in the second Chechen war, it was not the Russians who were the dominant actors, but the Chechens. Now Chechnya has become a mononational and monoreligious state entity. And it seems the re-frontier stage is over. But it is just after the Chechen war when the stage of reconsideration of the frontier and the role of the Russians in Chechen history starts, nostalgia for the times when the nations lived jointly arouses, the Russians are suggested to come back. Some scientific researches reinterpreting the intercultural links are carried out. $[16,17]$ In Dagestan refrontier manifested itself not in a form of positional warfare, but as long-lasting and regular terrorist actions, confrontations between traditionalists and supporters of moderate Islamization. Thus the reversible character of the frontier dynamics in the Caucasus is displayed. The idea of refrontier requires further consideration. It is also applicable to the studying of the Lower Volga region where as a result of constant migration from the Caucasus and Transcaucasia the ethno-confessional balance has changed and new confrontation of migrants with autochthonous ethnic groups, and in Kuban. The ideas of refrontier can be also applied to the analysis of the present situation in the Ukraine. We should study more comprehensively the main characteristics of this stage and type of frontier communications. Chechnya example shows that post-refrontier stage is also possible.

Thus we can see that the frontier thesis has preserved its meaning as a methodological research principle and got further momentum when new approaches and types appeared, researchers started to apply it to studying of new territories not in the historical aspect only, but in the aspect of modern social processes.

\section{Conclusion}

Application of the frontier methodology to studying cultural and political processes in the Caucasus helps to see the overall panorama and certain perspective of cultural communications in the region. In epistemological view it allows treating the zones of communicational tension not only as mistakes of the ruling authorities, but as a continuation of the frontier processes that took place in this territory since the time of its contact with another culture. It makes it possible to trace some regularities and forecast to some extent the further development of these types of frontier.

\section{References}

[1] Turner F. J. The frontier in American history. - N.Y.: Courier Dover Publications, 1996.

[2] Basalaeva I.P. Social and Philosophical Foundations of Frontier Concept by F.J. Tuner / Bulletin of Kemerovo State University of Culture and Arts 21/2012 pp.20-28; Criteria of Frontier: for Statement of the 
Question// Theory and Practice of Social Development: electronic journal. 2012. - URL: http://www.teoria-practica.ru/ (date of publication: 20.02.2012; 0.48 sheets). Frontier as a Place in Dimensional Analysis of Social Dynamics / I.P. Basalaeva // Bulletin of
Kemerovo State University of Culture and Arts. - 2012. - Num. 1 (18). - P. 208-214

[3] Shilovskiy M.V. Frontier and Migration (Siberian Experience) // Frontier in the History of Siberia and North America in the 17th-20th cc.: Common and Individual. Num.3. - Novosibirsk, 2003, p. 101. 